\title{
Allergenic Fragrances Analysis in Brazilian Perfumes by Headspace Solid Phase Microextraction and Gas Chromatography-Mass Detector (HS-SPME-GC-MS)
}

\author{
Clêrton L. Gomes, ${ }^{a, b}$ Ari C. A. de Lima, ${ }^{c}$ Pablo G. A. Barbosa, ${ }^{a}$ Rouse S. Costa, ${ }^{a}$ \\ Diego Q. Melo ${ }^{d}$ and Ronaldo F. Nascimento ${ }^{*, a}$
}

${ }^{a}$ Departamento de Química Analítica e Físico-Química, bloco 940, Centro de Ciências, Universidade Federal do Ceará, Campus do Pici, 60440-900 Fortaleza-CE, Brazil

${ }^{b}$ Instituto Federal de Educação, Ciência e Tecnologia do Ceará, Campus Aracati, 62800-000 Aracati-CE, Brazil

'Departamento de Engenharia Hidráulica e Ambiental, Bloco 713, Centro de Tecnologia, Universidade Federal do Ceará, Campus do Pici, 60440-900 Fortaleza-CE, Brazil

'Instituto Federal de Educação, Ciência e Tecnologia do Sertão Pernambucano, Campus Petrolina, 56314-520 Petrolina-PE, Brazil

\begin{abstract}
Perfumes are products mainly consisting of ethyl alcohol, water and fragrance. These fragrances are responsible for characterizing the pleasant and unique odor of each perfume. Among the fragrances, we highlight a group of fragrances which can cause contact allergy, leading to dermatitis. Brazilian and the European law state that when these concentrations of allergenic fragrances exceed the limit of $0.01 \%$ for non-rinse products and $0.001 \%$ for products with rinsing, the manufacturer is obliged to discriminate on its label their presence. This work aims to quantify allergic fragrances in original and Brazilian perfume using solid-phase microextraction and analyze by gas chromatography-mass detector.
\end{abstract}

Keywords: solid-phase microextraction, allergic fragrances, perfumes

\section{Introduction}

Perfumes are products of great importance in the cosmetic industry. Their essential fragrance composition is formed by ethanol and water, in which each product has a unique formulation which allows unique characteristics. ${ }^{1}$

Fragrances are volatile organic compounds and semi-volatile compounds which have pleasant scent characteristics. For this reason, they are used in perfumes or scented products of different purposes. ${ }^{2}$ Some of these fragrances when used by some individuals may manifest allergic reaction when they come into direct contact with skin. ${ }^{3}$ Clinical studies on this allergic reaction were carried out first in European Union and then Brazil to adopt more stringent legislation regarding these types of compounds., ${ }^{4,5}$

Some perfume components at high concentrations can cause allergic reactions. Among these compounds, stands out a group of allergic fragrances that, according to Resolution No. 3/2012 of the National Health Surveillance

*e-mail: ronaldo@ufc.br
Agency (ANVISA, Brazil), ${ }^{5}$ when found in excess $0.001 \%(\mathrm{~m} / \mathrm{m})$ and $0.01 \%(\mathrm{~m} / \mathrm{m})$ concentrations in products without and with rinsing, respectively, the dermocosmetic product should discriminate in its label their presence.

The gas chromatography mass spectrometry (GC-MS) is the most widely used technique in the analysis of fragrances. ${ }^{6,7}$ Other techniques have also been recently used such as two-dimensional gas chromatography coupled with flame ionization detector, ${ }^{8,9}$ electronic nose ${ }^{10}$ and electrospray ionization coupled to mass spectrometer. ${ }^{2,11}$

The literature reports some works on analysis of allergic fragrances in various matrices such as baby bathwater, ${ }^{4}$ fragrances,${ }^{8,9}$ cosmetics, ${ }^{12-14}$ shampoo,,${ }^{15}$ toys,${ }^{16}$ water types (pool and sewage), ${ }^{17}$ indoor air ${ }^{18}$ and fragrance oils. ${ }^{19}$

Due to the lack of studies in Brazil on products that can cause allergy and in order to assist the current health legislation, given the large market for skin cosmetics, we sought to investigate and quantify these compounds in perfume samples.

The aim of this work is to propose an analytical methodology for identification and quantification of allergic 
fragrances in Brazilian perfumes with minimal amounts of samples, using solid phase microextraction (SPME) and GC-MS.

\section{Experimental}

\section{Materials}

In this study were investigated the standards of allergenic fragrances: 3,7-dimethyl-1,6-octadien-3-ol (linalool, 97.2\%); 3,7-dimethyloct-6-en-1-ol (citronellol, 96.6\%); 2-methoxy-4-prop-2-enyl phenol (eugenol, 99.6\%); 2H-1-benzopyran-2-one (coumarin, 100\%); 3,7,11-trimethyldodeca-2,6,10-trien-1-ol (farnesol, 98\%); 3,7-dimethylocta-2,6-dienal (citral, 95.4\%); 4-methoxybenzene ethanol (anisyl alcohol, 99.8\%); 2-methoxy-4-(1-propenyl) phenol (isoeugenol, 100\%); 2-(phenylmethylene)-heptanal (amylcinnamaldehyde, 98.3\%); 3-phenyl phenylmethyl ester-2-propenoic acid (benzyl cinnamate, 100\%); 3-methyl-4-(2,6,6-trimethyl2-cyclohexen-1-yl)-3-buten-2-one ( $\alpha$-isomethylionone, 100\%); 3,7-dimethyl-2,6-octadien-1-ol (geraniol, 95.0\%); 2-(phenylmethylene)-1-heptanol (amylcinnamic alcohol, 96.0\%); 3-(4-tert-butylphenyl)-2-methylpropanal (lilial®, $100 \%)$; 4-(4-hydroxy-4-methylpentyl) cyclohex-3-ene1-carbaldehyde (lyral $\left.{ }^{\circledR}, 100 \%\right) ; 2$-hydroxyphenyl-methyl ester benzoic acid (benzyl salicylate, 100\%); 2-octynoic acid methyl ester (methyl 2-octynoate, 100\%); 7-hydroxy3,7-dimethyloctanal (hydroxycitronellal, 99.8\%); 3-phenyl2-propenal (cinnamaldehyde, 98.4\%); 2-(phenylmethylene) octanal (hexylcinnamic aldehyde, 100\%); and 3-phenyl2-propen-1-ol (cinnamic alcohol, 94.8\%) for $1000 \mathrm{mg} \mathrm{L}^{-1}$ concentration (Acunstandart, USA). SPME manual holders, $65 \mu$ m polydimethylsiloxane/divinylbenzene (PDMS/DVB) fibers and vial $40 \mathrm{~mL}$ supplied by Supelco (Bellefonte, PA, USA), methanol grade HPLC (Merck, Brazil), $\mathrm{NaCl}$ PA (Vetec, Brazil) and ultrapure water obtained from a Milli-Q water purification system (Millipore, Billerica, MA, USA) were also used.

\section{Samples}

A total number of 25 fragrances were acquired: 10 dealer perfumes of authorized Brazilian brand A (PA), 5 perfumes of authorized brand $\mathrm{B}(\mathrm{PB})$ and 10 similar perfumes of brand A (PSA) found in informal trade as shown in Table 1.

\section{Gas chromatography-mass spectrometry (GC-MS)}

The determination of the allergenic fragrance was performed on a gas chromatograph coupled with a mass
Table 1. Perfume sample: brand A, brand B and similar brand A

\begin{tabular}{lcc}
\hline Perfume & Type & Brand \\
\hline PA 1-10 & original & A \\
PB 1-5 & original & B \\
PSA 1-10 & similar & A \\
\hline
\end{tabular}

detector type quadrupole GC-MS-QP2010 Plus model (Shimadzu, Japan) equipped with a DB5 column (Agilent, USA) ( $30 \mathrm{~m}$ length, $0.25 \mathrm{~mm}$ internal diameter and $0.25 \mu \mathrm{m}$ film thickness, $5 \%$ phenyl and $95 \%$ polydimethylsiloxane). Helium (99.99\%) was used as the carrier gas at constant

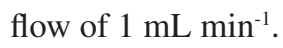

The mass spectrometer conditions were set as follows: ionization mode: electron ionization (EI), $70 \mathrm{eV}$; ion source temperature $220{ }^{\circ} \mathrm{C}$ and transfer line temperature $280{ }^{\circ} \mathrm{C}$. Quantitative analysis was performed in the selected ion monitoring (SIM) mode based on the use of one quantitative fragment and two or three qualitatives fragments. Tables 2 and 3 show the temperature program and the conditions of GC-MS and analyzed fragments. Table 3 shows the retention times of allergic fragrances and their quantitative and qualitative fragments used in SIM method.

Table 2. Chromatographic conditions

\begin{tabular}{|c|c|}
\hline Injector temperature $/{ }^{\circ} \mathrm{C}$ & 240 \\
\hline Mode & SIM \\
\hline Split & $1 / 30$ \\
\hline Transfer line temperature $/{ }^{\circ} \mathrm{C}$ & 280 \\
\hline Ion source temperature $/{ }^{\circ} \mathrm{C}$ & 220 \\
\hline Temperature programming & $\begin{array}{c}45^{\circ} \mathrm{C} \text {, hold } 2 \mathrm{~min} ; \\
8{ }^{\circ} \mathrm{C} \mathrm{min} \min ^{-1} \text { to } 100{ }^{\circ} \mathrm{C} ; \\
15{ }^{\circ} \mathrm{C} \min ^{-1} \text { to } 150{ }^{\circ} \mathrm{C} ; \\
20{ }^{\circ} \mathrm{C} \min ^{-1} \text { to } 200{ }^{\circ} \mathrm{C} ; \\
8{ }^{\circ} \mathrm{C} \min ^{-1} \text { to } 240{ }^{\circ} \mathrm{C} \text {, hold } 5 \mathrm{~min} \text {. } \\
\text { Total time } 24.50 \mathrm{~min}\end{array}$ \\
\hline Cutting time / min & 5.5 \\
\hline
\end{tabular}

Table 3. SIM mode: time and fragments

\begin{tabular}{lc}
\hline time $/$ min & Fragments \\
\hline $5.50-9.42$ & $68 ; 67 ; 93 ; 79 ; 108$ and 77 \\
$9.42-10.83$ & $71 ; 43$ and 41 \\
$10.83-18.97$ & $41 ; 95 ; 67 ; 69 ; 44 ; 68 ; 84 ; 131 ; 103 ; 132 ; 59 ; 43 ; 71 ;$ \\
& $92 ; 91 ; 78 ; 164 ; 149 ; 118 ; 146 ; 89 ; 77 ; 135 ; 107 ; 150 ;$ \\
& $189 ; 147 ; 115 ; 129 ; 117 ; 104 ; 79 ; 93 ; 133 ; 105 ; 65 ;$ \\
& $138 ; 109$ and 94 \\
$18.97-24.50$ & $91 ; 131$ and 77 \\
\hline
\end{tabular}

Analysis of allergic fragrance perfume by HS-SPME-GC-MS

Previously, a multi-element stock solution in methanol of $10,000 \mu \mathrm{g} \mathrm{L} \mathrm{L}^{-1}$ allergenic fragrances was prepared. The 
following dilutions of the multi-element stock solution,

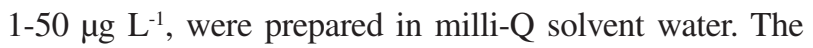
extraction of the compounds was carried out using $10 \mathrm{~mL}$ of solution by adding $2 \mathrm{~g} \mathrm{NaCl}$ and transferred to a $40 \mathrm{~mL}$ vial. The sealed vial was stirred $5 \mathrm{~min}$ at $100^{\circ} \mathrm{C}$. After this period, the fiber was exposed in a headspace (HS) for $20 \mathrm{~min}$. Shortly after the analytes extraction, the fiber was taken and brought to the remaining gun for $15 \mathrm{~min}$ for complete desorption of analytes in the GC injector. This method is based on the procedure adopted by Lamas et al. ${ }^{4}$ and Becerril et al. ${ }^{17}$

\section{Method validation}

Twenty one allergenic fragrances in perfumes were analyzed by HS-SPME-GC-MS. Validation parameters such as linearity, selectivity, limits of detection (LOD) and quantification (LOQ), accuracy and precision were determined according to guidelines of ANVISA-2003 and ABNT NBR 14029. ${ }^{20,21}$ The external standard analytical curves were plotted with proper amounts of standard solutions at the concentration range of $1-50 \mu \mathrm{g} \mathrm{L}^{-1}$. The significance test of the curves calibration parameters was based on a hypothesis test applying the parameter $t$ test (equations 1 and 2):

$t_{\text {calc }, \mathrm{A}}=\frac{|\mathrm{A}-\alpha|}{\mathrm{S}_{\mathrm{A}}}$

$t_{\text {calc,B }}=\frac{|\mathrm{B}-\beta|}{\mathrm{S}_{\mathrm{B}}}$

where $\mathrm{A}$ is the experimental angular coefficient; $\alpha=1$ is the theoretical angular coefficient; $t_{\text {calc, } A}$ is the $t$ value calculated for the slope; $\mathrm{S}_{\mathrm{A}}$ is the standard deviation of the slope; $\mathrm{B}$ is the experimental linear coefficient; $\beta=0$ is the theoretical linear coefficient; $S_{B}$ is the standard deviation of the intercept; $t_{\text {calc, }}$ is the $t$ value calculated for the intercept. ${ }^{22,23}$

LOD and LOQ values were estimated in the SIM mode analysis as the lowest concentration injected. The values for LOD and LOQ were calculated taking into account the standard deviation (SD) of repetitions $(n=7)$ of the chromatographic analysis of the lowest point $\left(1 \mu \mathrm{g} \mathrm{L}^{-1}\right)$ of the curve and the slope equation (AC) based on ANVISA ${ }^{20}$ (equations 3 and 4).

$$
\begin{aligned}
& \mathrm{LOD}=3.3 \times \frac{\mathrm{SD}}{\mathrm{AC}} \\
& \mathrm{LOQ}=10 \times \frac{\mathrm{SD}}{\mathrm{AC}}
\end{aligned}
$$

Precision of the method was evaluated by repeatability (intraday) and intermediate precision (interday) of sample solutions. The intermediate precision assays were performed in three levels of 1,10 and $30 \mu \mathrm{g} \mathrm{L}^{-1}$ for three consecutive days $(n=3)$ and repeatability tests at a level of $30 \mu \mathrm{g} \mathrm{L}^{-1}(\mathrm{n}=6)$. The results were expressed as \%RSD of the measurements. Accuracy of the method was tested with recovery experiments, performed with five replicates of blank samples spiked with 21 allergic fragrances $(5,10$ and $30 \mu \mathrm{g} \mathrm{L}^{-1}$ ) according to guidelines of ANVISA. ${ }^{20}$

\section{Results and Discussion}

\section{Selectivity}

In literature studies ${ }^{7,9,24,25}$ have been shown that for allergic fragrances analysis, GC-MS in SIM mode operating system is good option to the resolution of co-elution of some compounds, however, the two-dimensional chromatographic system has shown promise.

Figure 1 shows the total ion chromatogram (TIC) for all the studied compounds of the allergenic fragrance and can be observed some co-elution peaks. The co-elution occurred between citronellol (3) and anisyl alcohol (8); hydroxycitronellal (7) and citral isomer (4a); citral isomer (4b), cinnamaldehyde (6) and eugenol (10); cinnamic alcohol (9), $\alpha$-isomethylioneno (13) and lyral $^{\circledR}(16)$; coumarin and lilial ${ }^{\circledR}(12)$.

As can be seen in the Figure 1, the scan mode was not efficient to solve the problems of co-elution. Due to this, was chosen in order to work in SIM, because the it solved the co-elution problems and increase the sensibility, as shown in Figures 2-5.

The SIM method solves the problem of co-eluting compounds, for example, as can be seen in Figures 2 and 3, between the citral ( $\mathrm{m} / \mathrm{z}, 84$ and 94) and hydroxycitronellol $(\mathrm{m} / \mathrm{z}$ 59). In Figures 4 and 5 can be seen between anisyl alcohol ( $m / z$ 138) and citronellol $(\mathrm{m} / \mathrm{z} 41,67$ and 69). Table 4 shows the retention time and identification and quatitation fragments of the analytes (see Suplementary Information, Figures S1-S17).

Linearity

The calibration curves of the compounds related to allergic 21 fragrances and their correlation coefficients (R) are given in Table 5. It can be noted that all curves have an appropriate correlation coefficient value according to ANVISA. ${ }^{20}$ The curves obtained by external standard showed good linearity as well as the results obtained by Lamas et al. ${ }^{4}$ and Becerril et al. ${ }^{17}$ On the other hand, Debonneville and Chaintreau $^{9}$ and Leijs et al. ${ }^{19}$ investigated with success the 


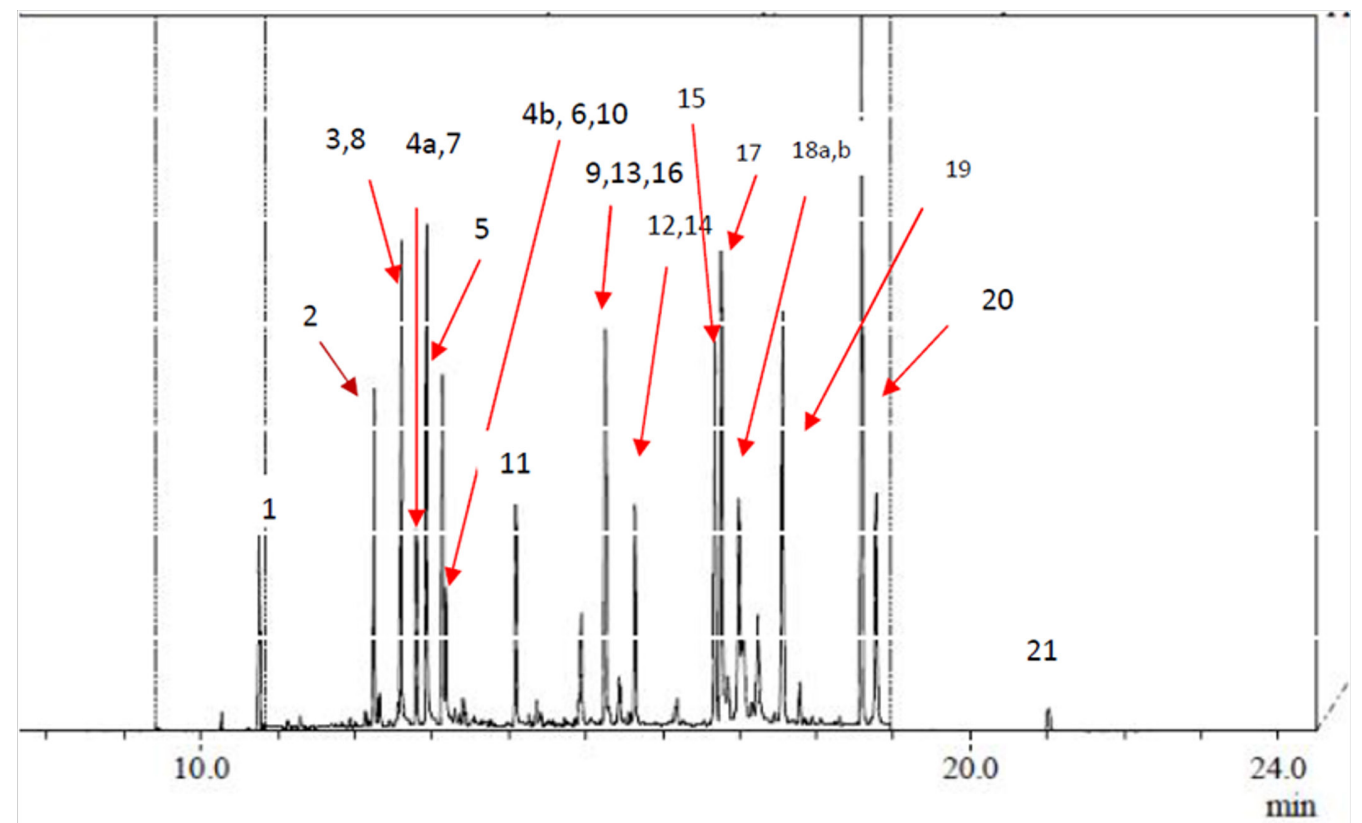

Figure 1. Total ion chromatogram (TIC) from the 21 allergic fragrances in scan mode: 1: linalool; 2: methyl 2-octynoate; 3: citronellol; 4a and 4b: citral; 5: geraniol; 6: cinnamaldehyde; 7: hydroxycitronellal; 8: anisyl alcohol; 9: cinnamic alcohol; 10: eugenol; 11: isoeugenol; 12: coumarin; 13: $\alpha$-isomethylioneno; 14: lilial ${ }^{\circ}$; 15: amylcinnamaldehyde; 16: lyral®; 17: amylcinnamic alcohol; 18a and 18b: farnesol; 19: hexylcinnamic aldehyde; 20: benzyl salicylate; and 21: benzyl cinnamate.

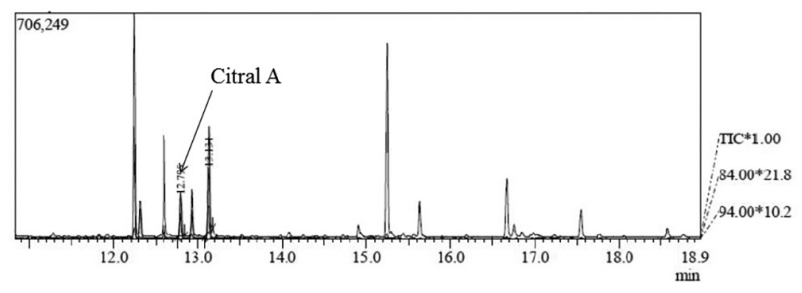

Figure 2. Chromatogram with citral fragments $(m / z, 84$ and 94$)$.

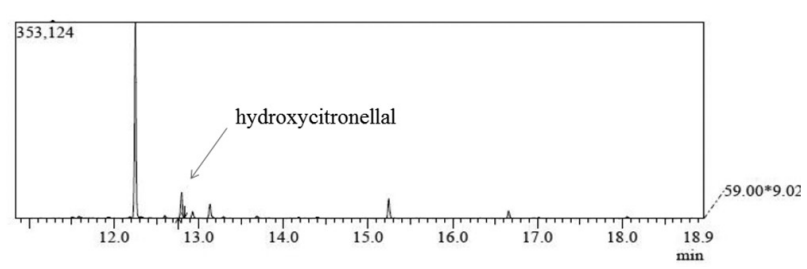

Figure 3. Chromatogram with hydroxycitronellal fragments $(\mathrm{m} / \mathrm{z}, 59)$.

use of two internal standards (1,4-dibromobenzene and 4,4-dibromobiphenyl) with direct injection.

Moreover, results of Table 5 showed that the technique of applying HS-SPME for those compounds did not require the use of an internal standard. However, the application of HS-SPME technique provides low limit of detection (at $\mu \mathrm{g} \mathrm{L}^{-1}$ ) for determination of these compounds within a very satisfactory linear range. The contrast was observed by studying only the headspace process as demonstrated by Sanchez et al..$^{14}$ which did not achieve a good linearity to the level of $\mu \mathrm{g} \mathrm{L}^{-1}$. These results are important from an analytical point of view, because, when working with level

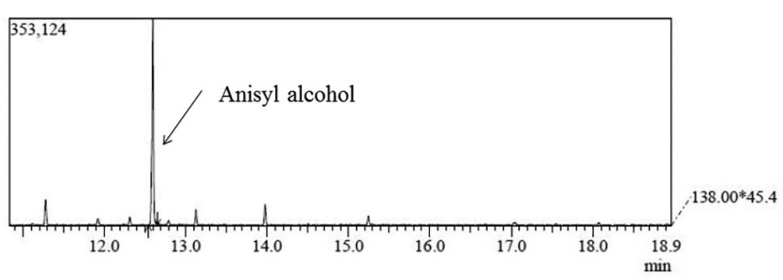

Figure 4. Chromatogram with anisyl alcohol fragments $(\mathrm{m} / \mathrm{z}, 138)$.

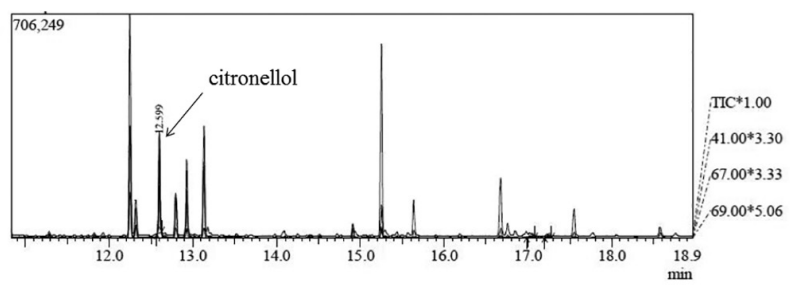

Figure 5. Chromatogram with citronellol fragments $(\mathrm{m} / \mathrm{z}, 41,67$ and 69).

of concentration in $\mu \mathrm{g} \mathrm{L}^{-1}$, small amounts of solutes can be quantified in analytical sample, minimizing the matrix effect, in addition to preserve the integrity of the instrument.

\section{Parameter significance testing of calibration curves}

Ideally, the regression lines obtained for the calibration curve should pass through the origin, that is, the intercept of the curve passing through the point $(0,0)$ of the Cartesian axes. In order to evaluate the statistical significance of the regression parameters $\mathrm{A}$ and $\mathrm{B}$, the models obtained experimentally for the calibration curves, it is useful to 
compare them with theoretically expected values $\alpha$ and $\beta$, with $\alpha=1$ and $\beta=0.2,22$
The significance test of the curves calibration parameters is based on a hypothesis test applying the parameter $t$ test.

Table 4. Retention time and identification and quatitation fragments of the analytes

\begin{tabular}{|c|c|c|c|}
\hline Compound & Retention time / min & Identification $(\mathrm{m} / \mathrm{z})$ & Quantification $(\mathrm{m} / \mathrm{z})$ \\
\hline Linalool & 10.75 & $41 ; 43 ; 71$ & $41 ; 43 ; 71$ \\
\hline Methyl 2-octynoate & 12.25 & $67 ; 95$ & 95 \\
\hline Citrolellol & 12.59 & $41 ; 67 ; 69$ & $41 ; 67 ; 69$ \\
\hline \multirow[t]{2}{*}{ Citral } & 12.8 & 84; 94 & $84 ; 94$ \\
\hline & 13.1 & $84 ; 94$ & $84 ; 94$ \\
\hline Geraniol & 12.9 & $41 ; 69$ & $41 ; 69$ \\
\hline Cinnamaldehyde & 13.15 & $77 ; 131$ & 131 \\
\hline Hydroxycitronellal & 12.75 & $59 ; 95$ & 59 \\
\hline Anisyl alcohol & 12.6 & $138 ; 109$ & 138 \\
\hline Cinnamic alcohol & 15.25 & $91 ; 92$ & 91 \\
\hline Eugenol & 13.2 & 103 & 103 \\
\hline Isoeuegenol & 14.09 & 164 & 164 \\
\hline Coumarin & 15.6 & $89 ; 118 ; 146$ & $89 ; 118 ; 146$ \\
\hline$\alpha$-Isomethylioneno & 15.25 & $107 ; 135 ; 150$ & $107 ; 135 ; 150$ \\
\hline Lilial® & 15.64 & $131 ; 189$ & $131 ; 189$ \\
\hline Amylcinnamaldehyde & 16.67 & $91 ; 115 ; 117$ & $91 ; 115 ; 117$ \\
\hline Lyral® & 15.25 & $59 ; 79$ & 79 \\
\hline Amylcinnamic alcohol & 16.98 & $91 ; 115 ; 133$ & 133 \\
\hline \multirow[t]{2}{*}{ Farnesol } & 17.1 & $69 ; 93$ & $69 ; 93$ \\
\hline & 17.25 & & \\
\hline Hexylcinnamic aldehyde & 17.55 & 129 & 129 \\
\hline Benzyl salicylate & 18.75 & $65 ; 91$ & 91 \\
\hline Benzyl cinnamate & 21.00 & $77 ; 91 ; 131$ & $77 ; 91 ; 131$ \\
\hline
\end{tabular}

Table 5. Calibration curves, correlation coefficient $(\mathrm{R})$ of the compounds studied in a concentration range $1-50 \mu \mathrm{g} \mathrm{L}^{-1}$

\begin{tabular}{|c|c|c|c|}
\hline Compound & Linear equation & Correlation coefficient & Number of points of curve \\
\hline Linalool & $y=20630 x+146779$ & 0.995 & 5 \\
\hline Methyl 2-octynoate & $y=70166 x-67715$ & 0.993 & 5 \\
\hline Citronellol & $y=67374 x+123450$ & 0.995 & 5 \\
\hline Citral & $y=49185 x-67703$ & 0.996 & 6 \\
\hline Geraniol & $y=3064.5 x-6021.9$ & 0.996 & 5 \\
\hline Cinnamaldehyde & $y=966.41 x+1917.2$ & 0.995 & 5 \\
\hline Hydroxycitronellal & $y=1577.1 x-1289.7$ & 0.995 & 5 \\
\hline Anisyl alcohol & $y=18865 x-56292$ & 0.999 & 5 \\
\hline Cinnamic alcohol & $y=1628 x-2761.9$ & 0.997 & 5 \\
\hline Eugenol & $y=2702.7 x-2161.7$ & 0.997 & 6 \\
\hline Isoeugenol & $y=50028 x-111773$ & 0.996 & 5 \\
\hline Coumarin & $y=142109 x-358103$ & 0.995 & 7 \\
\hline$\alpha$-Isomethylioneno & $y=4379.2 x-7989.7$ & 0.995 & 5 \\
\hline Lilial ${ }^{\circledR}$ & $y=128994 x-251554$ & 0.995 & 5 \\
\hline Amylcinnamaldehyde & $y=5565 x-14563$ & 0.995 & 5 \\
\hline Lyral® & $y=2172.9 x-947.43$ & 0.995 & 5 \\
\hline Amylcinnamic alcohol & $y=4608.5 x-3574.6$ & 0.996 & 7 \\
\hline Farnesol & $y=11347 x-26483$ & 0.997 & 5 \\
\hline Hexylcinnamic aldehyde & $y=14622 x-21988$ & 0.996 & 5 \\
\hline Benzyl salicylate & $y=70670 x-28904$ & 0.999 & 6 \\
\hline Benzyl cinnamate & $y=1787.8 x-2566.9$ & 0.995 & 5 \\
\hline
\end{tabular}


To evaluate the statistical significance of each regression parameter, standard deviations were obtained for the slopes and intercepts of the regression equations and values of the statistical parameter $t$ were calculated for each slope and intercept, according to equations 1 and $2 .{ }^{22,23}$ The calculated value of $t\left(t_{\text {calc }}\right)$ for the parameters was compared with the tabulated critical value of $t\left(t_{\text {crit }}\right)$, to a confidence level of $95 \%$ and the degree of freedom $(\mathrm{Df}=\mathrm{N}-2)$ for each calibration. When $t_{\text {calc }}$ is smaller than $t_{\text {crit }}$ the hypothesis that the difference between the calibration parameters obtained experimentally and theoretically expected value is accepted statistically insignificant, and then the experimental calibration parameters are considered equal to the theoretical value $(\alpha=1$ or $\beta=0)$. The results are shown in Table 6.

As can be seen in Table 6, the results of the statistical analysis of significance of the regression parameters showed that all inclinations are significant if $t_{\text {cal }, \mathrm{A}}>t_{\text {crit }}$. The

Table 6. Results of the statistical test of significance of the parameters of the calibration curves

\begin{tabular}{|c|c|c|c|c|c|c|c|c|}
\hline Compound & $\mathrm{S}_{\mathrm{a}}$ & $t_{\text {calc, } \mathrm{A}}$ & $\mathrm{S}_{\mathrm{b}}$ & $t_{\text {calc, B }}$ & Df & $t_{\mathrm{Df} ; 95 \%}$ & $t$ test & $\begin{array}{c}\text { Corrected calibration } \\
\text { curve }\end{array}$ \\
\hline Linalool & 1167.4 & 17.67 & 35984.3 & 4.08 & 3 & 3.18 & $\begin{array}{l}t_{\text {calc, } \mathrm{A}}>t_{\text {crit }} \\
t_{\text {calc, } \mathrm{B}}>t_{\text {crit }}\end{array}$ & $y=20630 x+146779$ \\
\hline Methyl 2-octynoate & 737.3 & 14.40 & 22904.9 & 2.27 & 3 & 3.18 & $\begin{aligned} t_{\text {calc, } \mathrm{A}} & >t_{\text {crit }} \\
t_{\text {calc,B }} & <t_{\text {crit }}\end{aligned}$ & $y=70166 x$ \\
\hline Citrolellol & 3848.9 & 18.23 & 102211.3 & 0.66 & 3 & 3.18 & $\begin{array}{l}t_{\text {calc, } \mathrm{A}}>t_{\text {crit }} \\
t_{\text {calc, } \mathrm{B}}<t_{\text {crit }}\end{array}$ & $y=67374 x$ \\
\hline Citral & $6.6 \times 10^{-7}$ & 4513155 & 1.4 & 1.17 & 4 & 2.78 & $\begin{array}{l}t_{\text {calc, } \mathrm{A}}>t_{\text {crit }} \\
t_{\text {calc, } \mathrm{B}}<t_{\text {crit }}\end{array}$ & $y=49185 x$ \\
\hline Geraniol & 1997.1 & 24.63 & 56743.10 & 1.19 & 5 & 2.57 & $\begin{array}{l}t_{\text {calc, } \mathrm{A}}>t_{\text {crit }} \\
t_{\text {calc, } \mathrm{B}}<t_{\text {crit }}\end{array}$ & $y=3064.5 x$ \\
\hline Cinnamaldehyde & $1.6 \times 10^{-5}$ & 193689.8 & 1.3 & 1.62 & 4 & 2.78 & $\begin{array}{l}t_{\text {calc, } \mathrm{A}}>t_{\text {crit }} \\
t_{\text {calc, } \mathrm{B}}<t_{\text {crit }}\end{array}$ & $y=966.41 x$ \\
\hline Hydroxycitronellal & 53.0 & 18.20 & 1564.9 & 1.22 & 3 & 3.18 & $\begin{array}{l}t_{\text {calc, } \mathrm{A}}>t_{\text {crit }} \\
t_{\text {calc, } \mathrm{B}}<t_{\text {crit }}\end{array}$ & $y=1577.1 x$ \\
\hline Anisyl alcohol & 7.9 & 198.57 & 256.6 & 2.03 & 3 & 3.18 & $\begin{aligned} t_{\text {calc, } \mathrm{A}} & >t_{\text {crit }} \\
t_{\text {calc, }, \mathrm{B}} & <t_{\text {crit }}\end{aligned}$ & $y=18865 x$ \\
\hline Cinnamic alcohol & 849.0 & 22.22 & 21646.7 & 2.60 & 3 & 3.18 & $\begin{aligned} t_{\text {calc,A }}>t_{\text {crit }} \\
t_{\text {calc,B }}<t_{\text {crit }}\end{aligned}$ & $y=1628 x$ \\
\hline Eugenol & 76.1 & 21.39 & 2055.7 & 1.34 & 3 & 3.18 & $\begin{aligned} t_{\text {calc, } \mathrm{A}} & >t_{\text {crit }} \\
t_{\text {calc, }, \mathrm{B}} & <t_{\text {crit }}\end{aligned}$ & $y=2702.7 x$ \\
\hline Isoeuegenol & $1.6 \times 10^{-5}$ & 183659.1 & 2.00 & 0.77 & 4 & 2.78 & $\begin{array}{l}t_{\text {calc, } \mathrm{A}}>t_{\text {crit }} \\
t_{\text {calc, } \mathrm{B}}<t_{\text {crit }}\end{array}$ & $y=50028 x$ \\
\hline Coumarin & 3478.0 & 14.38 & 93984.1 & 1.19 & 3 & 3.18 & $\begin{array}{l}t_{\text {calc, } \mathrm{A}}>t_{\text {crit }} \\
t_{\text {calc, } \mathrm{B}}<t_{\text {crit }}\end{array}$ & $y=142109 x$ \\
\hline$\alpha$-Isomethylioneno & $4.2 \times 10^{-7}$ & 7163847 & 1.4 & 1.95 & 4 & 2.78 & $\begin{array}{l}t_{\text {calc, } \mathrm{A}}>t_{\text {crit }} \\
t_{\text {calc, }, \mathrm{B}}<t_{\text {crit }}\end{array}$ & $y=4379.2 x$ \\
\hline Lilial@ & 271.8 & 16.10 & 6929.9 & 1.15 & 3 & 3.18 & $\begin{array}{l}t_{\text {calc, } \mathrm{A}}>t_{\text {crit }} \\
t_{\text {calc, } \mathrm{B}}<t_{\text {crit }}\end{array}$ & $y=128994 x$ \\
\hline Amylcinnamaldehyde & 7364.2 & 17.52 & 198996.5 & 1.26 & 3 & 3.18 & $\begin{aligned} t_{\text {calc, } \mathrm{A}} & >t_{\text {crit }} \\
t_{\text {calc }, \mathrm{B}} & <t_{\text {crit }}\end{aligned}$ & $y=5565 x$ \\
\hline Lyral® & $1.3 \times 10^{-5}$ & 290242.3 & 1.37 & 2.08 & 4 & 2.78 & $\begin{aligned} t_{\text {calc, } \mathrm{A}} & >t_{\text {crit }} \\
t_{\text {calc,B }} & <t_{\text {crit }}\end{aligned}$ & $y=2172.9 x$ \\
\hline Amylcinnamic alcohol & 81.6 & 26.61 & 2399.2 & 0.39 & 5 & 2.57 & $\begin{array}{l}t_{\text {calc, } \mathrm{A}}>t_{\text {crit }} \\
t_{\text {calc,B }}>t_{\text {crit }}\end{array}$ & $y=4608.5 x$ \\
\hline Farnesol & $7.6 \times 10^{-6}$ & 391873.2 & 1.04 & 0.86 & 4 & 2.78 & $\begin{aligned} t_{\text {calc, } \mathrm{A}} & >t_{\text {crit }} \\
t_{\text {calc,B }} & <t_{\text {crit }}\end{aligned}$ & $y=11347 x$ \\
\hline Hexylcinnamic aldehyde & $4.0 \times 10^{-6}$ & 758154.8 & 1.27 & 1.98 & 4 & 2.78 & $\begin{array}{l}t_{\text {calc, } \mathrm{A}}>t_{\text {crit }} \\
t_{\text {calc, }, \mathrm{B}}<t_{\text {crit }}\end{array}$ & $y=14622 x$ \\
\hline Benzyl salicylate & $3.4 \times 10^{-6}$ & 891759.7 & 1.33 & 1.47 & 4 & 2.78 & $\begin{array}{l}t_{\text {calc, } \mathrm{A}}>t_{\text {crit }} \\
t_{\text {calc, }, \mathrm{B}}<t_{\text {crit }}\end{array}$ & $y=70670 x$ \\
\hline Benzyl cinnamate & 101.7 & 17.57 & 2812.3 & 0.91 & 3 & 3.18 & $\begin{array}{l}t_{\text {calc, }}>t_{\text {crit }} \\
t_{\text {calc., }}<t_{\text {crit }}\end{array}$ & $y=1787.8 x$ \\
\hline
\end{tabular}

$\mathrm{S}_{\mathrm{a}}$ : standard deviation of the slope; $\mathrm{S}_{\mathrm{b}}$ : standard deviation of the intercept; $t_{\text {calc, } \mathrm{A}}: t$ value calculated for the slope; $t_{\text {calc, } \mathrm{B}}: t$ value calculated for the intercept; Df: degree of freedom; $t_{\mathrm{Df} 995 \%}$ : Student's $t$-test with confidence level of $95 \%$. 
intercept, with the exception of the compound of linalool curve, is not significant, considering that $t_{\text {calc, }}<t_{\text {crit }}$ and was considered as statistically equal to $\beta$, which has a value of zero reference. Therefore, the equations of the curves applied to the calculations of the analytes concentrations are the ones shown in Table 6, with a 95\% confidence level. Among the tested compounds, the only compound which shows the statistically significant linear coefficient is linalool.

\section{Limits of detection (LOD) and quantification (LOQ)}

The results for the limits of detection (LOD) and quantification (LOQ) are shown in Table 7. The LOD and LOQ values calculated in this work took into account the standard deviation $(\mathrm{SD})$ of repetitions $(n=7)$ of the chromatographic analysis of the lowest point $\left(1 \mu \mathrm{g} \mathrm{L}^{-1}\right)$ of the curve and the slope equation (AC) based on ANVISA. ${ }^{20}$

Table 7. Limit of detection (LOD) and limit of quantification (LOQ) of allergic fragrances

\begin{tabular}{lcc}
\hline Compound & LOD / $\left(\mu \mathrm{g} \mathrm{L}^{-1}\right)$ & $\left.\mathrm{LOQ} /(\mu \mathrm{g} \mathrm{L})^{-1}\right)$ \\
\hline Linalool & 0.074 & 0.247 \\
Methyl 2-octynoate & 0.043 & 0.142 \\
Citronellol & 0.008 & 0.027 \\
Citral & 0.017 & 0.057 \\
Geraniol & 0.040 & 0.135 \\
Cinnamaldehyde & 0.245 & 0.878 \\
Hydroxycitronellal & 0.239 & 0.797 \\
Anisyl alcohol & 0.712 & 0.234 \\
Cinnamic alcohol & 0.043 & 0.143 \\
Eugenol & 0.270 & 0.900 \\
Isoeugenol & 0.064 & 0.215 \\
Coumarin & 0.202 & 0.674 \\
$\alpha$-Isomethylioneno & 0.201 & 0.670 \\
Lilial@ & 0.101 & 0.338 \\
Amylcinnamaldehyde & 0.005 & 0.017 \\
Lyral® & 0.243 & 0.810 \\
Amylcinnamic alcohol & 0.252 & 0.840 \\
Farnesol & 0.074 & 0.248 \\
Hexylcinnamic aldehyde & 0.211 & \\
Benzyl salicylate & & 0.702 \\
Benzyl cinnamate & 0.210 & \\
\hline & & \\
\hline
\end{tabular}

\section{Precision}

The analysis of the coefficient of variation values $(\mathrm{CV} \%)$, repeatability and intermediate precision showed values ranging from 2.6 to $19.2 \%$, as seen in Table 8 . According to ANVISA, an acceptable value is around 5\%; however, because of the magnitude of these compounds in the sample to the level $1 \mu \mathrm{g} \mathrm{L}^{-1}$, other references ${ }^{20,21,26}$ also accept a variation coefficient value of up to $20 \%$. Therefore, our results can be considered acceptable, because, according to the norm of ABNT NBR $14029,{ }^{21}$ which stipulates that for a chemical analysis of the magnitude 10-100 $\mu \mathrm{g} \mathrm{L}^{-1}$, the value of coefficient of variation between 23 to $32 \%$ is accepted, although this rule is for pesticide analysis at this level of concentration.

Our results of intermediate precision presented values lower than $20 \%$, however the literature reports results lower than $10 \%$. However, values obtained in this study $(1,10$ and $30 \mu \mathrm{g} \mathrm{L}^{-1}$ ) do not follow a quantitative standard for intermediate precision as expected, but it was also observed in other studies. ${ }^{17}$ Analyzing the CV\% for the repeatability study in Table 8 , it can be seen that the values were above $15 \%$. These values are acceptable according to the standard 14029 of ABNT-NBR. ${ }^{21}$ However, when compared to literature data, ${ }^{17}$ it is noted that the $\mathrm{CV}$ values obtained are less than $10 \%$, but these results are for concentration of $20 \mu \mathrm{g} \mathrm{L}^{-1}$. Therefore, as in this work the concentration of the compounds studied was $30 \mu \mathrm{g} \mathrm{L} \mathrm{L}^{-1}$, then the difference in the $\mathrm{CV}$ values may be due to this fact.

\section{Recovery}

Recovery results were satisfactory for most of the 21 compounds analyzed according to ANVISA standard. ${ }^{20}$ Looking at Table 9, the compounds which showed poor recovery were cinnamic alcohol (10 and $\left.30 \mu \mathrm{g} \mathrm{L}^{-1}\right)$ and lilial $\left(30 \mu \mathrm{g} \mathrm{L}^{-1}\right)$, but considering the RSD these results are consistent with current regulations of $70-120 \%$. The comparison of the recovery values obtained with literature data $\mathrm{a}^{4,17}$ indicates that our values are lower. This can be explained by the complex nature of the perfume composition, which can interfere with the recovery rate of the studied compounds.

\section{Analysis of perfumes}

From the results of the analyzes of perfumes (Table 10), it can be observed the presence of some of these fragrances in high concentrations that can cause allergy and thus they need to be informed in the products' labels for consumers' knowledge and meet the current legislation. Among the fragrances studied it was observed that the original perfumes (brands A and B) present allergenic fragrances in high concentrations for all the range of molar weight of the compounds. However, for the similar perfumes was not observed for fragrances with high molar weight, such as benzyl cinnamate and hexylcinnamic aldehyde. This can 
Table 8. Intermediate precision and repeatability of allergic fragrances

\begin{tabular}{|c|c|c|c|c|}
\hline \multirow{2}{*}{ Compound } & \multicolumn{3}{|c|}{ Intermediate precision } & \multirow{2}{*}{$\begin{array}{c}\text { Repeatability } \\
30 \mu \mathrm{g} \mathrm{L}^{-1}(\mathrm{n}=6)\end{array}$} \\
\hline & $1 \mu \mathrm{g} \mathrm{L}^{-1}(\mathrm{n}=3)$ & $10 \mu \mathrm{g} \mathrm{L}^{-1}(\mathrm{n}=3)$ & $30 \mu \mathrm{g} \mathrm{L}^{-1}(\mathrm{n}=3)$ & \\
\hline Linalool & $4.4(6.4)^{\mathrm{a}}$ & $2.6(12)^{\mathrm{b}}$ & $19.3(4.6)^{\mathrm{c}}$ & $16.3(1)^{\mathrm{d}}$ \\
\hline Methyl 2-octynoate & $9.7(8.6)^{\mathrm{a}}$ & $6.9(12)^{b}$ & $13.6(8.6)^{\mathrm{c}}$ & $8.6(1)^{\mathrm{d}}$ \\
\hline Citronellol & $1.6(8.7)^{\mathrm{a}}$ & $3.1(7.9)^{\mathrm{b}}$ & $10.2(6.5)^{\mathrm{c}}$ & $14.0(9.6)^{\mathrm{d}}$ \\
\hline Citral & $8.2(1.2)^{\mathrm{a}}$ & $6.2(3.4)^{\mathrm{b}}$ & $10.9(2.9)^{\mathrm{c}}$ & $15.6(0.8)^{\mathrm{d}}$ \\
\hline Geraniol & $14.9(6.6)^{\mathrm{a}}$ & $8.3(5.3)^{\mathrm{b}}$ & $13.3(2.5)^{\mathrm{c}}$ & $13.9(0.6)^{\mathrm{d}}$ \\
\hline Cinnamaldehyde & $13.3(7.7)^{\mathrm{a}}$ & $5.6(12)^{\mathrm{b}}$ & $7.5(4.3)^{\mathrm{c}}$ & $13.0(1)^{\mathrm{d}}$ \\
\hline Hydroxycitronellal & $15.3(4.3)^{\mathrm{a}}$ & $4.1(11)^{\mathrm{b}}$ & $16.4(3.7)^{\mathrm{c}}$ & $15.2(3.6)^{\mathrm{d}}$ \\
\hline Anisyl alcohol & $15.8(3.6)^{\mathrm{a}}$ & $11.9(11)^{\mathrm{b}}$ & $18.4(6.0)^{\mathrm{c}}$ & $15.4(7.1)^{\mathrm{d}}$ \\
\hline Cinnamic alcohol & $4.4(5.3)^{\mathrm{a}}$ & $5.7(5.4)^{\mathrm{b}}$ & $10.9(7.5)^{\mathrm{c}}$ & $16.2(5.9)^{\mathrm{d}}$ \\
\hline Eugenol & $15.4(6.5)^{\mathrm{a}}$ & $10.7(6.6)^{b}$ & $4.8(3.9)^{\mathrm{c}}$ & $15.7(2.8)^{\mathrm{d}}$ \\
\hline Isoeugenol & $6.6(6.3)^{\mathrm{a}}$ & $13.9(0.6)^{\mathrm{b}}$ & $3.7(2.4)^{\mathrm{c}}$ & $6.7(3)^{\mathrm{d}}$ \\
\hline Coumarin & $6.5(7.1)^{\mathrm{a}}$ & $13.5(7.7)^{\mathrm{b}}$ & $9.8(3.7)^{\mathrm{c}}$ & $17.5(4.3)^{\mathrm{d}}$ \\
\hline$\alpha$-Isomethylioneno & $3.1(7.0)^{\mathrm{a}}$ & $5.4(2.5)^{\mathrm{b}}$ & $11.2(0.8)^{\mathrm{c}}$ & $13.8(0.9)^{\mathrm{d}}$ \\
\hline Lilial® & $3.0(4.8)^{\mathrm{a}}$ & $11.3(4.8)^{\mathrm{b}}$ & $8.7(3.0)^{\mathrm{c}}$ & $16.3(1.6)^{\mathrm{d}}$ \\
\hline Amylcinnamaldehyde & $9.5(4.6)^{\mathrm{a}}$ & $16.9(8.9)^{\mathrm{b}}$ & $6.3(3.7)^{\mathrm{c}}$ & $19.7(2.5)^{\mathrm{d}}$ \\
\hline Lyral® & $18.0(11)^{\mathrm{a}}$ & $7.4(17)^{\mathrm{b}}$ & $12.5(3.2)^{\mathrm{c}}$ & $8.9(1.4)^{\mathrm{d}}$ \\
\hline Amylcinnamic alcohol & $14.3(5.9)^{\mathrm{a}}$ & $11.4(5.5)^{\mathrm{b}}$ & $15.5(4.3)^{\mathrm{c}}$ & $14.4(0.8)^{\mathrm{d}}$ \\
\hline Farnesol & $10.2(7.1)^{\mathrm{a}}$ & $11.2(6.3)^{b}$ & $13.9(1.9)^{\mathrm{c}}$ & $16.8(1.4)^{\mathrm{d}}$ \\
\hline Hexylcinnamic aldehyde & $3.6(4.0)^{\mathrm{a}}$ & $5.9(8.8)^{\mathrm{b}}$ & $13.2(3.3)^{\mathrm{c}}$ & $16.1(2.5)^{\mathrm{d}}$ \\
\hline Benzyl salicylate & $16.8(11)^{\mathrm{a}}$ & $17.9(3.2)^{\mathrm{b}}$ & $7.3(9.2)^{\mathrm{c}}$ & $15.6(7.6)^{\mathrm{d}}$ \\
\hline Benzyl cinnamate & $13.6(12)^{\mathrm{a}}$ & $12.0(15)^{\mathrm{b}}$ & $12.8(5.3)^{\mathrm{c}}$ & $19.2(6.8)^{\mathrm{d}}$ \\
\hline
\end{tabular}

${ }^{\text {IIntermediate precision } 5 \mu \mathrm{g} \mathrm{L}-1}(\mathrm{~N}=5) ;{ }^{17}$ intermediate precision $10 \mu \mathrm{g} \mathrm{L}{ }^{-1}(\mathrm{~N}=5) ;{ }^{17}$ cintermediate precision $20 \mu \mathrm{g} \mathrm{L}{ }^{-1}(\mathrm{~N}=5) ;{ }^{17} \mathrm{depeatability} 20 \mu \mathrm{g} \mathrm{L}{ }^{-1}$ $(\mathrm{N}=3) \cdot{ }^{17}$

Table 9. Recovery of allergic fragrances

\begin{tabular}{|c|c|c|c|}
\hline \multirow{2}{*}{ Compound } & \multicolumn{3}{|c|}{ Recovery (RSD) / \% } \\
\hline & $5 \mu \mathrm{g} \mathrm{L}^{-1}(\mathrm{n}=3)$ & $10 \mu \mathrm{g} \mathrm{L}^{-1}(\mathrm{n}=3)$ & $30 \mu \mathrm{g} \mathrm{L}^{-1}(\mathrm{n}=3)$ \\
\hline Linallol & $70 \pm 13.1$ & $111 \pm 8.3$ & $75 \pm 8.4$ \\
\hline Methyl 2-octynoate & $72 \pm 11.3$ & $88 \pm 4.9$ & $92 \pm 5.7$ \\
\hline Citronellol & $90 \pm 5.8$ & $80 \pm 11.5$ & $107 \pm 6.3$ \\
\hline Citral & $70 \pm 6.7$ & $88 \pm 7.4$ & $98 \pm 9.7$ \\
\hline Geraniol & $86 \pm 8.4$ & $73 \pm 13.6$ & $76 \pm 6.2$ \\
\hline Cinnamaldehyde & $83 \pm 7.9$ & $77 \pm 10.5$ & $94 \pm 8.2$ \\
\hline Hydroxycitronellal & $69 \pm 7.5$ & $87 \pm 9.1$ & $105 \pm 6.6$ \\
\hline Anisyl alcohol & $78 \pm 12.1$ & $86 \pm 7.2$ & $82 \pm 12.4$ \\
\hline Ainnamic alcohol & $86 \pm 8.7$ & $59 \pm 4.5$ & $66 \pm 10.3$ \\
\hline Eugenol & $78 \pm 9.5$ & $76 \pm 5.7$ & $103 \pm 8.1$ \\
\hline Isoeugenol & $89 \pm 13.2$ & $82 \pm 4.8$ & $110 \pm 4.8$ \\
\hline Coumarin & $103 \pm 7.1$ & $94 \pm 6.9$ & $88 \pm 12.9$ \\
\hline$\alpha$-Isomethylioneno & $73 \pm 4.9$ & $113 \pm 4.2$ & $109 \pm 8.4$ \\
\hline Lilial@ & $87 \pm 7.7$ & $66 \pm 11.2$ & $89 \pm 3.9$ \\
\hline Amylcinnamaldehyde & $86 \pm 9.4$ & $114 \pm 8.2$ & $101 \pm 11.9$ \\
\hline Lyral® & $72 \pm 6.9$ & $115 \pm 9.0$ & $112 \pm 7.9$ \\
\hline Amylcinnamic alcohol & $81 \pm 4.7$ & $90 \pm 6.6$ & $87 \pm 7.4$ \\
\hline Farnesol & $80 \pm 7.3$ & $111 \pm 8.9$ & $78 \pm 4.9$ \\
\hline Hexylcinnamic aldehyde & $92 \pm 5.9$ & $85 \pm 5.4$ & $98 \pm 9.6$ \\
\hline Benzyl salicylate & $71 \pm 8.7$ & $93 \pm 8.5$ & $102 \pm 5.3$ \\
\hline Benzyl cinnamate & $103 \pm 6.8$ & $99 \pm 10.1$ & $88 \pm 8.1$ \\
\hline
\end{tabular}


Table 10. Result analysis fragrances in original perfumes and similar

\begin{tabular}{|c|c|c|c|c|c|c|c|c|c|c|c|c|}
\hline \multirow[b]{2}{*}{ Sample } & \multicolumn{12}{|c|}{ Concentration / $\left(\mathrm{mg} \mathrm{L}^{-1}\right)$} \\
\hline & Linalool & $\begin{array}{c}\text { Methyl } \\
\text { 2-octynoate }\end{array}$ & Citronellol & Citral & Geraniol & Cinnamaldehyde & $\begin{array}{l}\text { Hydroxy } \\
\text { citronellal }\end{array}$ & $\begin{array}{l}\text { Anisyl } \\
\text { alcohol }\end{array}$ & $\begin{array}{c}\text { Cinnamic } \\
\text { alcohol }\end{array}$ & Eugenol & Isoeugenol & Coumarin \\
\hline PA1 & $<$ LOD & $<$ LOD & $<$ LOD & $<\mathrm{LOD}$ & 58.9 & $<$ LOD & 31.5 & $<$ LOD & 16.2 & 22.2 & 28.2 & $<$ LOD \\
\hline PA2 & 50.2 & $<\mathrm{LOD}$ & 8.6 & 19.8 & 60.5 & $<$ LOD & $<$ LOD & $<$ LOD & $<$ LOD & $<$ LOD & $<$ LOD & 21 \\
\hline PA3 & 30.9 & $<$ LOD & $<$ LOD & 12.3 & 82.5 & $<$ LOD & 15.2 & $<$ LOD & $<$ LOD & 13.7 & 25.6 & 47.9 \\
\hline PA4 & 8.8 & $<$ LOD & 7.4 & $<$ LOD & 11 & $<$ LOD & 9.0 & $<$ LOD & $<$ LOD & 19.1 & $<$ LOD & 13.5 \\
\hline PA5 & 41.6 & $<\mathrm{LOD}$ & $<$ LOD & 9.9 & 52.1 & 8.9 & $<$ LOD & $<$ LOD & 9.0 & 182.5 & 24.8 & 81.1 \\
\hline PA6 & 42.1 & $<\mathrm{LOD}$ & $<$ LOD & 42.1 & 77.8 & $<$ LOD & 32.9 & $<$ LOD & $<$ LOD & $<$ LOD & $<$ LOD & 42.9 \\
\hline PA7 & 14.1 & $<$ LOD & 9.1 & $<$ LOD & 1.1 & 2.1 & 25.9 & $<$ LOD & $<$ LOD & $<$ LOD & $<$ LOD & $<$ LOD \\
\hline PA8 & 11.5 & $<$ LOD & $<$ LOD & 19 & 42.4 & 1.9 & 13 & $<$ LOD & $<$ LOD & 9.1 & 66.5 & 10.3 \\
\hline PA9 & $<$ LOD & $<$ LOD & 4.7 & 1.4 & 22 & 38.7 & $<$ LOD & $<$ LOD & $<$ LOD & $<$ LOD & $<$ LOD & $<$ LOD \\
\hline PA10 & 12.7 & $<\mathrm{LOD}$ & 5.5 & 7.0 & 22.2 & 1.3 & 34.2 & $<$ LOD & $<$ LOD & $<$ LOD & $<$ LOD & $<$ LOD \\
\hline PB1 & 46.4 & $<\mathrm{LOD}$ & 8.7 & 10 & 77.4 & 1.7 & 11.7 & $<$ LOD & $<$ LOD & $<$ LOD & $<$ LOD & $<$ LOD \\
\hline PB2 & $<\mathrm{LOD}$ & $<$ LOD & 19.8 & 6.0 & 46.5 & $<$ LOD & 7.0 & $<$ LOD & 12.3 & $<$ LOD & $<$ LOD & 41.7 \\
\hline PB3 & 35.4 & $<$ LOD & 13.7 & 1.1 & 21.3 & $<$ LOD & $<$ LOD & $<$ LOD & $<$ LOD & 11 & $<$ LOD & $<$ LOD \\
\hline PB4 & 30.0 & $<$ LOD & 11.2 & 8.3 & 31 & 6.3 & 9.0 & $<$ LOD & $<$ LOD & 10.4 & $<$ LOD & $<$ LOD \\
\hline PB5 & 36.3 & $<$ LOD & $<$ LOD & 17.2 & 86.5 & 1.6 & 14.1 & $<$ LOD & 13.5 & 19 & $<$ LOD & 34.5 \\
\hline PSA1 & 31.4 & $<\mathrm{LOD}$ & 6.7 & 8.2 & 56.5 & $<$ LOD & $<$ LOD & $<$ LOD & $<\mathrm{LOD}$ & 1.2 & 1.4 & $<$ LOD \\
\hline PSA2 & 14.7 & $<\mathrm{LOD}$ & 8.0 & 3.5 & 28.2 & $<$ LOD & $<$ LOD & $<$ LOD & $<\mathrm{LOD}$ & $<$ LOD & $<$ LOD & $<$ LOD \\
\hline PSA3 & $<\mathrm{LOD}$ & $<\mathrm{LOD}$ & 1.0 & 1.4 & 19.2 & $<$ LOD & 1.3 & $<$ LOD & $<\mathrm{LOD}$ & $<$ LOD & 1.3 & 5.6 \\
\hline PSA4 & $<$ LOD & $<$ LOD & 10.6 & $<$ LOD & 23.4 & $<$ LOD & $<$ LOD & $<$ LOD & $<$ LOD & 1.9 & 1.1 & 0.0 \\
\hline PSA5 & 17.7 & $<$ LOD & 13.7 & $<$ LOD & 2.0 & $<$ LOD & $<$ LOD & $<$ LOD & $<$ LOD & $<$ LOD & $<$ LOD & 1.8 \\
\hline PSA6 & 2.2 & $<$ LOD & $<$ LOD & $<$ LOD & 46.8 & $<$ LOD & 10.6 & $<$ LOD & $<$ LOD & 8.3 & $<$ LOD & $<$ LOD \\
\hline PSA7 & 17.6 & $<$ LOD & $<$ LOD & $<$ LOD & $<$ LOD & $<$ LOD & $<$ LOD & $<$ LOD & $<$ LOD & $<$ LOD & $<$ LOD & $<$ LOD \\
\hline PSA8 & 34.9 & $<\mathrm{LOD}$ & $<$ LOD & 7.2 & 34.0 & $<$ LOD & $<$ LOD & $<$ LOD & $<\mathrm{LOD}$ & 1.6 & $<$ LOD & $<$ LOD \\
\hline PSA9 & 12.6 & $<\mathrm{LOD}$ & $<\mathrm{LOD}$ & $<$ LOD & 19.2 & $<$ LOD & 2.6 & $<$ LOD & $<\mathrm{LOD}$ & 2.3 & $<$ LOD & $<$ LOD \\
\hline PSA10 & 8.4 & $<$ LOD & 6.6 & $<$ LOD & 28.8 & $<$ LOD & $<$ LOD & $<$ LOD & $<$ LOD & 1.7 & $<$ LOD & $<$ LOD \\
\hline & & & & & & Concentration & $/\left(\mathrm{mg} \mathrm{L}^{-1}\right)$ & & & & & \\
\hline Sample & $\begin{array}{c}\alpha \text {-Isomethyl } \\
\text { ioneno }\end{array}$ & Lilial ${ }^{\circledR}$ & Amylcinna & aldehyde & Lyral ${ }^{\circledR}$ & Amylcinnamic & c alcohol & Farnesol & Hexylcinnar & ic aldehyde & $\begin{array}{c}\text { Benzyl } \\
\text { salicylate }\end{array}$ & $\begin{array}{c}\text { Benzyl } \\
\text { cinnamate }\end{array}$ \\
\hline PA1 & 36.1 & 164.7 & $<\mathrm{L}$ & & 31.0 & $<\mathrm{LOD}$ & & 30.7 & $<\mathrm{L}$ & & $<$ LOD & $<$ LOD \\
\hline PA2 & $<\mathrm{LOD}$ & $<\mathrm{LOD}$ & $<\mathrm{L}$ & & $<\mathrm{LOD}$ & $<$ LOD & & $<\mathrm{LOD}$ & 39 & & $<$ LOD & $<$ LOD \\
\hline PA3 & $<$ LOD & 128.5 & $<\mathrm{L}$ & & 16.6 & $<$ LOD & & 31.1 & $<\mathrm{L}$ & & 7.1 & $<$ LOD \\
\hline PA4 & $<$ LOD & $<$ LOD & $<\mathrm{L}$ & & 7.0 & $<$ LOD & & 8.2 & 12 & & 1.3 & $<$ LOD \\
\hline PA5 & 32.7 & 162.8 & $<\mathrm{L}$ & & 29.9 & $<\mathrm{LOD}$ & & $<$ LOD & $<\mathrm{L}$ & & $<$ LOD & $<$ LOD \\
\hline PA6 & 1.5 & 76.1 & $<\mathrm{L}$ & & $<\mathrm{LOD}$ & 22.1 & & $<$ LOD & 16 & & 2.3 & $<$ LOD \\
\hline PA7 & $<\mathrm{LOD}$ & 43.5 & $<\mathrm{L}$ & & $<\mathrm{LOD}$ & 2.4 & & 34.6 & $<\mathrm{L}$ & & 37.4 & $<$ LOD \\
\hline PA8 & $<$ LOD & 15.0 & $<\mathrm{L}$ & & $<$ LOD & $<$ LOD & & $<$ LOD & 2 & & $<$ LOD & $<$ LOD \\
\hline PA9 & $<\mathrm{LOD}$ & 9.4 & $<\mathrm{L}$ & & 12.9 & 14.9 & & $<\mathrm{LOD}$ & 3 & & 55.7 & $<$ LOD \\
\hline PA10 & $<$ LOD & $<$ LOD & $<\mathrm{L}$ & & $<$ LOD & $<\mathrm{LOD}$ & & $<$ LOD & $<\mathrm{L}$ & & $<$ LOD & $<$ LOD \\
\hline PB1 & 13.1 & 106.6 & $<\mathrm{L}$ & & 11.3 & 8.3 & & $<$ LOD & $<\mathrm{L}$ & & 190 & $<$ LOD \\
\hline PB2 & 17.4 & 51.2 & $<\mathrm{L}$ & & 26.5 & 14.1 & & $<$ LOD & 1 & & 14.2 & $<$ LOD \\
\hline PB3 & 9.4 & 48.8 & $<\mathrm{L}$ & & $<$ LOD & 9.1 & & $<$ LOD & $<\mathrm{L}$ & & 3.3 & $<\mathrm{LOD}$ \\
\hline PB4 & 11.2 & 46.4 & $<\mathrm{L}$ & & 12.6 & 7.5 & & $<$ LOD & $<\mathrm{L}$ & & 30.1 & $<$ LOD \\
\hline PB5 & $<$ LOD & 8.7 & $<\mathrm{L}$ & & $<$ LOD & 12.5 & & $<$ LOD & 12 & & $<$ LOD & $<$ LOD \\
\hline PSA1 & 3.0 & 3.5 & $<\mathrm{L}$ & & $<\mathrm{LOD}$ & $<\mathrm{LOD}$ & & $<\mathrm{LOD}$ & $<\mathrm{L}$ & & $<\mathrm{LOD}$ & $<\mathrm{LOD}$ \\
\hline PSA2 & 1.5 & 2.6 & $<\mathrm{L}$ & & $<$ LOD & $<$ LOD & & $<$ LOD & $<\mathrm{L}$ & & $<$ LOD & $<$ LOD \\
\hline PSA3 & $<$ LOD & 8.8 & $<\mathrm{L}$ & & $<$ LOD & $<\mathrm{LOD}$ & & $<$ LOD & $<\mathrm{L}$ & & $<$ LOD & $<$ LOD \\
\hline PSA4 & 2.3 & 22.7 & $<\mathrm{L}$ & & $<$ LOD & $<\mathrm{LOD}$ & & $<$ LOD & $<\mathrm{L}$ & & $<$ LOD & $<$ LOD \\
\hline PSA5 & $<$ LOD & 9.6 & $<\mathrm{L}$ & & $<$ LOD & $<\mathrm{LOD}$ & & $<$ LOD & $<\mathrm{L}$ & & $<$ LOD & $<$ LOD \\
\hline PSA6 & $<$ LOD & 6.9 & $<\mathrm{L}$ & & $<$ LOD & $<$ LOD & & $<$ LOD & $<\mathrm{L}$ & & $<$ LOD & $<$ LOD \\
\hline PSA7 & $<\mathrm{LOD}$ & 1.9 & $<\mathrm{L}$ & & $<\mathrm{LOD}$ & $<\mathrm{LOD}$ & & $<\mathrm{LOD}$ & $<\mathrm{L}$ & & $<\mathrm{LOD}$ & $<\mathrm{LOD}$ \\
\hline PSA8 & $<$ LOD & $<$ LOD & $<\mathrm{L}$ & & $<$ LOD & $<$ LOD & & $<$ LOD & $<\mathrm{L}$ & & $<$ LOD & $<$ LOD \\
\hline PSA9 & 2.8 & 4.7 & $<\mathrm{L}$ & & $<$ LOD & $<$ LOD & & $<$ LOD & $<\mathrm{L}$ & & $<$ LOD & $<$ LOD \\
\hline PSA10 & $<$ LOD & 4.7 & $<\mathrm{L}$ & & $<$ LOD & $<$ LOD & & $<$ LOD & $<\mathrm{L}$ & & $<$ LOD & $<$ LOD \\
\hline
\end{tabular}


be explained due to the low capacity of scent fixation of similars perfumes when compared to originals.

\section{Conclusion}

This technique can be used for analysis of allergic fragrance perfume using small amount of sample for analysis. This study may be a help to ANVISA in the control of allergic fragrances in perfumes. The results indicate that the similar perfumes do not present allergenic fragrances with high molecular weight, which influences an inferior scent fixation when compared to the original perfumes.

\section{Supplementary Information}

Supplementary data are available free of charge at http://jbcs.sbq.org.br as PDF file.

\section{Acknowledgments}

Thanks to the funders of the research project CNPq (Proc. No. 304888/2014-1), FUNCAP, CAPES and Department of Analytical Chemistry and PhysicalChemistry, Federal University of Ceará.

\section{References}

1. Gomes, C. L.; Lima, A. C. A.; Cândido, M. C. L.; Silva, A B. R.; Loyola, A. R. L.; Nascimento, R. F.; J. Braz. Chem. Soc. 2015, 26, 1730.

2. Haddad, R.; Catharino, R. R.; Marques, L. A.; Eberlin, M. N.; Rapid Commun. Mass Spectrom. 2008, 22, 3662.

3. Davies, R. F.; Jhonston, G. A.; Dermatol. Clin. 2011, 29, 311.

4. Lamas, J. P.; Sanchez- Prado, L.; Garcia-Jares, C.; Llompart, M.; Anal. Bioanal. Chem. 2010, 397, 2579.

5. ANVISA; Resolução-RDC No 3; Listas de Substâncias que os Produtos de Higiene Pessoal, Cosméticos e Perfumes Não Devem Conter Exceto nas Condições e com as Restrições Estabelecidas, Agência Nacional de Vigilância Sanitária, Brasilia, Brazil, 2012.

6. Asten, A. V.; Trends Anal. Chem. 2002, 21, 69.

7. Chaintreau, A.; Joulain, D.; Marin, C.; Schimith, C. O.; Vey, M.; J. Agric. Food Chem. 2003, 51, 6398.
8. Sheillie, R.; Marriott, P.; Chaintreau, A.; Flavour Fragrance J. 2004, 19, 91 .

9. Debonneville, C.; Chaintreau, A.; J. Chromatogr. A 2004, 1027, 109.

10. Cano, M.; Borrego, V.; Roales, J.; Idígoras, J.; Lopez-Costa, T.; Mendoza, P.; Pedrosa, J. M.; Sens. Actuators B 2011, 156, 319.

11. Marques, L. A.; Catharino, R. R.; Bruns, R. E.; Eberlin, M. N.; Rapid Commun. Mass Spectrom. 2006, 20, 3654.

12. Sgorbini, B.; Ruosi, M. R.; Cordero, C.; Liberto, E.; Rubiolo, P.; Bicchi, C.; J. Chromatogr. A 2010, 1217, 2599.

13. Niederer, M.; Bollhalder, R.; Hohl, Ch.; J. Chromatogr. A 2006, 1132, 109.

14. Sanchez, N. M.; Pérez-Pavón, J. L.; Cordero, B. M.; Anal. Bioanal. Chem. 2010, 397, 2579.

15. Chen, Y.; Begnaud, F.; Chaintreau, A.; Pawliszyn, J.; Flavour Fragrance J. 2006, 21, 822.

16. Masuck, I.; Hutzler, C.; Luch, A.; J. Chromatogr. A 2010, 1217 , 3136.

17. Becerril, E.; Lamas, J. P.; Sanchez-Prado, L.; Llompart, M.; Lores, M.; Garcia-Jares, C.; Talanta 2010, 83, 464.

18. Lamas, J. P.; Sanchez- Prado, L.; Garcia-Jares. C.; Llompart, M.; J. Chromatogr. A 2010, 1217, 1882.

19. Leijs, H.; Broekhans, J.; Pelt, L. V.; Mussinan, C.; J. Agric. Food Chem. 2005, 53, 5487.

20. Ellendt, K.; Hempel, G.; Köbler, H.; SOFW J. 2001, 127, 29.

21. Shellie, R.; Marriott, P.; Chaintreau, A.; Flavour Fragrance J. 2004, 19, 91.

22. ANVISA; Resolução RE No. 899.; Guia para Validação de Métodos Analíticos e Bioanalíticos, Agência Nacional de Vigilância Sanitária, Brasilia, Brazil, 2012.

23. ABNT NBR 14029; Agrotóxicos e Afins - Validação de Métodos Analíticos, Associação Brasileira de Normas Técnicas (ABNT), Rio de Janeiro, Brazil, 2005.

24. Ribani, M.; Bottoli, C. B. G.; Collins, C. H.; Jardim, I. C. S. F.; Melo, L. F. C.; Quim. Nova 2004, 27, 771.

25. Ligiero, C. B. P.; Reis, L. A.; Parrilha, G. L.; Baptista Filho, M.; Canela, M. C.; Quim. Nova 2009, 32, 1338.

26. Guedes, J. A. C.; Silva, I. R. O.; Lima, C. G.; Milhome, M. A. L; Nascimento, R. F.; Food Chem. 2016, 199, 380.

Submitted: October 24, 2016

Published online: March 31, 2017 